\title{
Ozone depletion due to increasing anthropogenic trace gas emissions: role of stratospheric chemistry and implications for future climate
}

\author{
M. Lal*, T. Holt \\ Climatic Research Unit, University of East Anglia, Norwich NR4 7TJ, United Kingdom
}

\begin{abstract}
The response of the atmosphere to increasing emissions of radiatively active trace gases $\left(\mathrm{CO}_{2}, \mathrm{CH}_{4}, \mathrm{~N}_{2} \mathrm{O}, \mathrm{O}_{3}\right.$ and CFCs) is calculated by means of a 1-dimensional coupled chemical-radiativetransport model. We identify the sign and magnitude of the feedback between the chemistry and thermal structure of the atmosphere by examining steady state changes in stratospheric ozone and surface temperature in response to perturbations in trace gases of anthropogenic origin. Next, we assess the possible decline in stratospheric ozone and its effect on troposphere-stratosphere temperature trends for the period covering the pre-industrial era to the present. Future trends are also considered using projected 'business-as-usual' trace gas scenario (scenario BAU) and that expected as a result of global phase-out of production of CFCs by the year 2000 (scenario MP). The numerical experiments take account of the effect of stratospheric aerosol loading due to volcanic eruptions and the influence of the thermal inertia of the ocean. Results indicate that the trace gas increase from the period 1850 to 1986 could already have contributed to a 3 to $10 \%$ decline in stratospheric ozone and that this decline is expected to become more pronounced by the year 2050, amounting to a $43 \%$ ozone loss at $40 \mathrm{~km}$ for the scenario BAU. The total column ozone increase of $1.5 \%$ obtained in our model calculations for the present-day atmosphere is likely to change sign with time leading to a net decrease of $12.7 \%$ by the middle of next century. The equilibrium surface warming for the period 1850 to 1986 is found to be $0.7 \mathrm{~K}$ and our calculations indicate that this warming will reach $2.6 \mathrm{~K}$ by the year 2050 . As a result of radiativechemical interactions, a large stratospheric cooling $(16.4 \mathrm{~K})$ is likely by the middle of the next century. In case the control measures on production of CFCs as laid down in the London Amendment of the Montreal Protocol are implemented by all countries and a global phase-out of CFCs takes place by the year 2000 , the ozone loss at $40 \mathrm{~km}$ could be restricted to $17 \%$ by the year 2050 (net column decrease of only $2.9 \%$ ). This would, however, only marginally reduce the stratospheric cooling to $12.6 \mathrm{~K}$. The greenhouse warming at the surface expected by the middle of the next century with enforcement of the Montreal Protocol restrictions is likely to be $2 \mathrm{~K}$.
\end{abstract}

\section{INTRODUCTION}

Trace gases play an important role in the atmosphere through their interaction with solar and terrestrial radiation and consequent effects on global climate. There has been much concern that increased anthropogenic release of trace gases such as $\mathrm{CO}_{2}, \mathrm{CH}_{4}, \mathrm{~N}_{2} \mathrm{O}$ and chlorofluorocarbons (CFCs) from industrial, agricultural and domestic activities will, in addition to enhancing the greenhouse effect, significantly modify the chemical composition of the atmosphere. This could

\footnotetext{
- Visiting Scientist. Permanent affiliation is with the Centre for Atmospheric Sciences, Indian Institute of Technology, 110016 New Delhi, India
}

lead to a substantial reduction in the density of stratospheric ozone with consequent climatic effects.

Recent findings linking the rise in chlorine (a byproduct of extensive CFC build-up in the atmosphere over the past 3 decades) and oxides of nitrogen (due to emissions from aircraft) to the destruction of stratospheric ozone (Prather \& Watson 1990) have stimulated renewed interest in the development of interactive chemistry-climate models. Such models may be used to diagnose the combined effect of physical and chemical processes, thus including both direct and indirect radiative effects, and to assess potential changes associated with future trace gas emissions to the atmosphere. However, modelling the behaviour of minor trace constituents in the atmosphere is a difficult task if 
radiative, chemical and dynamical processes are taken into account simultaneously. Until recently, only a few 3-dimensional modelling studies with explicit chemistry have been reported and most of these have a limited number of reactions in their chemical schemes (Cariolle \& Déqué 1986, Rose 1986, Rood et al. 1987. Kaye \& Rood 1989). Due to the exceedingly large computing requirements of such models it could be many years before a 3-dimensional photochemical-climate model, incorporating mutually-interactive radiative, chemical and dynamical components as well as the exchange processes within the ocean-atmosphere system, can be developed. Simplified approaches using 1and 2-dimensional models to study the sensitivity of global climate to increases in anthropogenic trace gas emissions have, therefore, been followed extensively in the past (Brühl \& Crutzen 1984, 1988, Wang \& Molnar 1985, Vupputuri 1988, Kinnison et al. 1988, Lal \& Jain 1989). These models include detailed representations of atmospheric radiative and/or chemical processes, giving a better understanding of the basic greenhouse mechanisms by which atmospheric trace gases warm the Earth's surface so that the effects can be scaled appropriately in complex 3-dimensional general circulation models (GCMs) (Lal \& Ramanathan 1984).

To obtain a new perspective on the effect of stratospheric chlorine and nitrogen on ozone photochemistry, and its implications for the thermal structure of the Earth-atmosphere system, we have developed a 1-dimensional coupled chemical-radiative-transport model. This model has been adapted in this study to investigate the possible effect of past to present anthropogenic emissions of major trace gases on atmospheric ozone and the contribution of ozone to greenhouse warming. Using future projections of trace gases under the 'business-as-usual' scenario as well as the scenario with controls on production of CFCs restricted to $50 \%$ of its 1986 level by the year 1995 and a complete phase-out by the year 2000 (scenarios BAU and MP), the potential role of chemistry-radiation interactions on future climatic trends is also examined.

\section{THE MODEL}

The 1-dimensional chemical-radiative-transport model developed at the Indian Institute of Technology, Delhi (IITD) is used in this study. The model combines the radiative-convective ( $\mathrm{RC}$ ) model described in Lal \& Jain (1989) with a photochemical transport model. The model atmosphere is divided into 16 vertical layers extending from the surface up to $55 \mathrm{~km}$ and represents the annual mean thermal structure of the global atmosphere at equilibrium. The model also has 2 layers in the ocean, the first being $50 \mathrm{~m}$ in thickness and treated as the oceanic mixed layer, while the lower layer extends to $500 \mathrm{~m}$. The atmospheric mixed layer is coupled to the oceanic mixed layer through the energy balance equation. Starting with a prescribed vertical distribution of temperature, cloud altitude and fraction, and chemical composition of the atmosphere, the photochemical sources and sinks and the associated solar and thermal flux divergences are computed for each layer using a time-marching method to infer the surface and atmospheric temperatures. To account for upward heat transfer we adapt the moist adiabatic adjustment scheme in the model troposphere to ensure that the column undergoing convective adjustment conserves mass, internal energy and moist static energy. The model has fixed relative humidity and the mixing ratio of water vapour is computed as a function of temperature. The radiative effects of optically active trace gases, namely $\mathrm{CO}_{2}, \mathrm{O}_{3}, \mathrm{CH}_{4}, \mathrm{~N}_{2} \mathrm{O}$ and CFCs, are treated in addition to that of water vapour.

The solar radiation absorbed by the model atmosphere is parametrized as a function of altitude such that the form of the solution and the coefficients involved are based on accurate multiple scattering computations. The parametrization is a function of the zenith angle of the Sun, the albedo of the Earth's surface, water vapour distribution, $\mathrm{CO}_{2}$ and $\mathrm{O}_{3}$ distributions, and the cloud cover. The band absorptance formulation of Lacis \& Hansen (1974) for $\mathrm{H}_{2} \mathrm{O}$ and $\mathrm{O}_{3}$ is used. The formulation of Ramanathan \& Cess (1974) has been adopted to account for the $\mathrm{CO}_{2}$ band. Solar heating due to reflection by clouds and the surface is also included. Rayleigh scattering due to air molecules and Mie scattering due to aerosols have been incorporated following the approximation to the Adding scheme (Cess et al. 1981).

Long wave radiative flux calculations use an approximate method of accounting for the integration of the optical path length over all solid angles. The vibrationrotation bands of $\mathrm{CO}_{2}$ and $\mathrm{O}_{3}$, and the vibration-rotation bands, pure rotation bands and continuum bands of $\mathrm{H}_{2} \mathrm{O}$ have been treated in terms of a combination of emissivity and band absorptance formulations. Many isotopic and hot bands for $\mathrm{CO}_{2}, \mathrm{~N}_{2} \mathrm{O}$ and $\mathrm{CH}_{4}$ are also included. Radiative transfer due to the $9.6 \mu \mathrm{m}$ band of $\mathrm{O}_{3}$ and the $15 \mu \mathrm{m} \mathrm{CO}_{2}$ band are treated according to the band absorptance formulation of Ramanathan (1976). The exponential-sum-fitting method has been applied to account for CFCs. Mutual overlap between $\mathrm{H}_{2} \mathrm{O}, \mathrm{CO}_{2}, \mathrm{O}_{3}, \mathrm{CH}_{4}, \mathrm{~N}_{2} \mathrm{O}$ and $\mathrm{CFCs}$ is also accounted for following Kiehl \& Ramanathan (1983). For further details on the computational aspects of the model, the reader is referred to Lal \& Jain (1989).

The photochemical model coupled with the RC model includes a series of relevant chemical reactions responsible for altering the concentration of ozone and 
other trace constituents in the upper atmosphere. Table 1 lists the photochemical and chemical reactions considered in the model. Four families of species, namely $\mathrm{O}_{x}$, $\mathrm{NO}_{x}, \mathrm{Cl}_{x}$, and $\mathrm{HO}_{x}$ are simulated. CFCs, $\mathrm{CH}_{4}, \mathrm{~N}_{2} \mathrm{O}$ and $\mathrm{H}_{2} \mathrm{O}$ are treated individually in the model. The formation of $O_{x}$ resulting from the photo-decomposition of molecular oxygen as well as its destruction by the Chapman reactions and the catalytic effects of $\mathrm{HO}_{x}$, $\mathrm{NO}_{x}$ and $\mathrm{Cl}_{x}$ are explicitly included. Water is specified by a tropopause boundary condition and the sources of the $\mathrm{HO}_{x}$ free radicals are the reaction of $\mathrm{H}_{2} \mathrm{O}$ with singlet atomic oxygen, photolysis of $\mathrm{H}_{2} \mathrm{O}$, and the reaction of $\mathrm{CH}_{4}$ with singlet atomic oxygen, atomic chlorine and HO (WMO 1985). Methane is transported from the troposphere and its derivatives are included in the $\mathrm{HO}_{x}$ family. The sources of the nitrogen oxide family $\left(\mathrm{NO}_{x}\right)$ are the reaction in the stratosphere of singlet atomic oxygen with $\mathrm{N}_{2} \mathrm{O}$ that rises from the troposphere or which is directly injected in the lower stratosphere. $\mathrm{Cl}_{x}$ perturbations are based on increases of $\mathrm{CCl}_{4}, \mathrm{CFCl}_{3}$, $\mathrm{CF}_{2} \mathrm{Cl}_{2}$ and $\mathrm{CH}_{3} \mathrm{CCl}_{3}$.

The spectral distribution of the solar irradiance required to compute photo-dissociation rates associated with photochemical reactions is taken from Brasseur \& Simon (1981) and WMO (1985). The absorption cross-sections and the rate constants for the reactions are based on those recommended by the NASA Panel for Data Evaluation (DeMore et al. 1985, 1987, 1990). The concentration of a chemical species based on net photochemical production/loss is governed by an eddy diffusion coefficient which is prescribed as a function of altitude $\left(1 \times 10^{5} \mathrm{~cm}^{2} \mathrm{~s}^{-1}\right.$ in the troposphere, $1 \times 10^{3} \mathrm{~cm}^{2}$ $\mathrm{s}^{-1}$ in the stratosphere and $1 \times 10^{4} \mathrm{~cm}^{2} \mathrm{~s}^{-1}$ above 45 $\mathrm{km}$ ). Full diurnal variation is taken into account. Clouds

Table 1 Principal chemical and photochemical reactions adopted in the model

$$
\begin{aligned}
& \mathrm{O}_{2}+\mathrm{h} v \rightarrow \mathrm{O}+\mathrm{O} \\
& \mathrm{O}_{3}+\mathrm{hv} \rightarrow \mathrm{O}_{2}+\mathrm{O} \\
& \mathrm{O}_{3}+\mathrm{h} v \rightarrow \mathrm{O}\left({ }^{1} \mathrm{D}\right)+\mathrm{O}_{2} \\
& \mathrm{NO}+\mathrm{hv} \rightarrow \mathrm{N}+\mathrm{O} \\
& \mathrm{NO}_{2}+\mathrm{hv} \rightarrow \mathrm{NO}+\mathrm{O} \\
& \mathrm{N}_{2} \mathrm{O}+\mathrm{hv} \rightarrow \mathrm{N}_{2}+\mathrm{O} \\
& \mathrm{NO}_{3}+\mathrm{hv} \rightarrow \mathrm{NO}_{2}+\mathrm{O} \\
& \mathrm{N}_{2} \mathrm{O}_{5}+\mathrm{hv} \rightarrow \mathrm{NO}_{2}+\mathrm{NO}_{3} \\
& \mathrm{H}_{2} \mathrm{O}+\mathrm{hv} \rightarrow \mathrm{H}+\mathrm{OH} \\
& \mathrm{H}_{2} \mathrm{O}_{2}+\mathrm{hv} \rightarrow \mathrm{OH}+\mathrm{OH} \\
& \mathrm{HNO}_{3}+\mathrm{hv} \rightarrow \mathrm{OH}+\mathrm{NO}_{2} \\
& \mathrm{HNO}_{4}+\mathrm{hv} \rightarrow \mathrm{NO}_{2}+\mathrm{HO}_{2} \\
& \mathrm{HOCl}+\mathrm{hv} \rightarrow \mathrm{OH}+\mathrm{Cl} \\
& \mathrm{HCl}+\mathrm{h} v \rightarrow \mathrm{H}+\mathrm{Cl} \\
& \mathrm{ClONO}_{2}+\mathrm{hv} \rightarrow \mathrm{ClO}+\mathrm{NO}_{2} \\
& \mathrm{CCl}_{4}+\mathrm{hv} \rightarrow \text { products } \\
& \mathrm{CH}_{3} \mathrm{CCl}_{3}+\mathrm{hv} \rightarrow \text { products } \\
& \mathrm{CF}_{2} \mathrm{Cl}_{2}+\mathrm{hv} \rightarrow \mathrm{CF}_{2} \mathrm{Cl}+\mathrm{Cl} \\
& \mathrm{CFCl}_{3}+\mathrm{hv} \rightarrow \mathrm{CFCl}_{2}+\mathrm{Cl} \\
& \mathrm{H}_{2} \mathrm{CO}+\mathrm{hv} \rightarrow \mathrm{H}+\mathrm{HCO} \\
& \mathrm{O}\left({ }^{1} \mathrm{D}\right)+\mathrm{H}_{2} \rightarrow \mathrm{H}+\mathrm{OH} \\
& O\left({ }^{1} D\right)+N_{2} \rightarrow O\left({ }^{3} p\right)+N_{2} \\
& \mathrm{O}\left({ }^{1} \mathrm{D}\right)+\mathrm{O}_{2} \rightarrow \mathrm{O}\left({ }^{3} p\right)+\mathrm{O}_{2} \\
& \mathrm{O}\left({ }^{\mathrm{D}} \mathrm{D}\right)+\mathrm{CH}_{4} \rightarrow \mathrm{CH}_{3}+\mathrm{OH} \\
& \mathrm{O}\left({ }^{3} \mathrm{D}\right)+\mathrm{CCl}_{4} \rightarrow \text { products } \\
& \mathrm{O}\left({ }^{1} \mathrm{D}\right)+\mathrm{H}_{2} \mathrm{O} \rightarrow \mathrm{OH}+\mathrm{OH} \\
& \mathrm{O}\left({ }^{1} \mathrm{D}\right)+\mathrm{N}_{2} \mathrm{O} \rightarrow 2 \mathrm{NO} \\
& \mathrm{O}\left({ }^{1} \mathrm{D}\right)+\mathrm{N}_{2} \mathrm{O} \rightarrow \mathrm{N}_{2}+\mathrm{O}_{2} \\
& \mathrm{O}\left({ }^{3} p\right)+\mathrm{NO}_{2} \rightarrow \mathrm{NO}+\mathrm{O}_{2} \\
& \mathrm{O}+\mathrm{O}+\mathrm{M} \rightarrow \mathrm{O}_{2}+\mathrm{M} \\
& \mathrm{O}+\mathrm{O}_{2}+\mathrm{M} \rightarrow \mathrm{O}_{3}+\mathrm{M} \\
& \mathrm{O}+\mathrm{O}_{3} \rightarrow 2 \mathrm{O}_{2} \\
& \mathrm{H}+\mathrm{O}_{2}+\mathrm{M} \rightarrow \mathrm{HO}_{2}+\mathrm{M} \\
& \mathrm{H}+\mathrm{O}_{3} \rightarrow \mathrm{O}_{2}+\mathrm{OH} \\
& \mathrm{H}+\mathrm{HO}_{2} \rightarrow \mathrm{H}_{2} \mathrm{O}+\mathrm{O} \\
& \mathrm{H}+\mathrm{HO}_{2} \rightarrow \mathrm{H}_{2}+\mathrm{O}_{2} \\
& \mathrm{OH}+\mathrm{O} \rightarrow \mathrm{H}+\mathrm{O}_{2} \\
& \mathrm{OH}+\mathrm{O}_{3} \rightarrow \mathrm{HO}_{2}+\mathrm{O}_{2} \\
& \mathrm{OH}+\mathrm{OH} \rightarrow \mathrm{H}_{2} \mathrm{O}+\mathrm{O} \\
& \mathrm{OH}+\mathrm{HO}_{2} \rightarrow \mathrm{H}_{2} \mathrm{O}+\mathrm{O}_{2} \\
& \mathrm{OH}+\mathrm{H}_{2} \mathrm{O}_{2} \rightarrow \mathrm{H}_{2} \mathrm{O}+\mathrm{HO}_{2}
\end{aligned}
$$

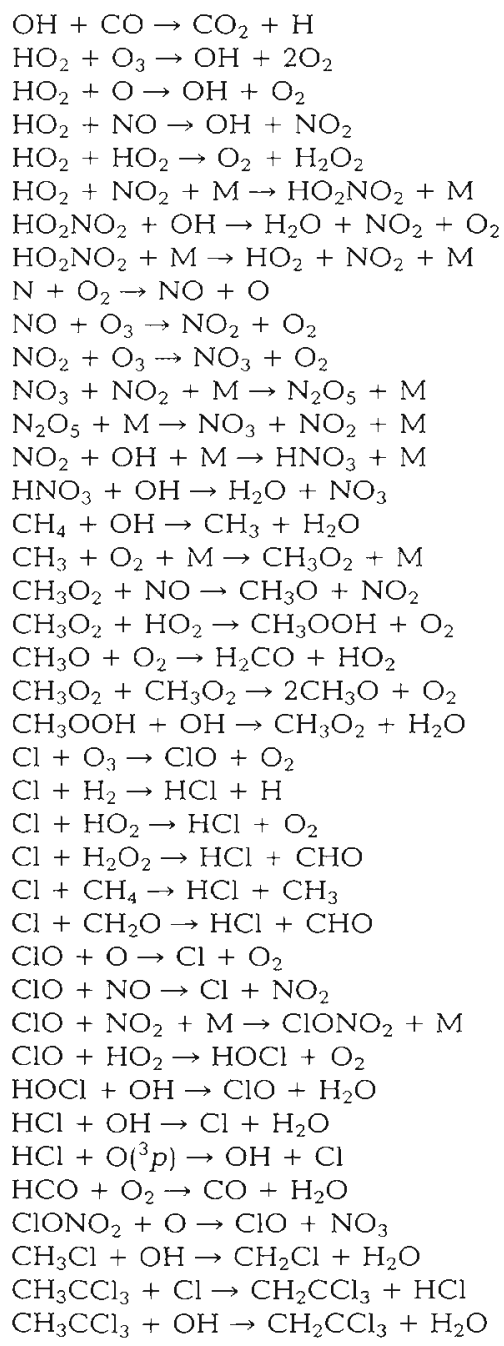


Table 2. Estimates of abundance of trace gases in the global atmosphere

\begin{tabular}{|c|c|c|c|}
\hline $\begin{array}{l}\text { Trace } \\
\text { gas }\end{array}$ & Year 1850 & $\begin{array}{l}\text { Mixing ratio in ppbv } \\
\text { Year } 1986\end{array}$ & Year 2050 (BAU) \\
\hline $\mathrm{CO}_{2}$ & $270 \times 10^{3}$ & $341 \times 10^{3}$ & $500 \times 10^{3}$ \\
\hline $\mathrm{N}_{2} \mathrm{O}$ & $280^{a}$ & 302 & 400 \\
\hline $\mathrm{CH}_{4}$ & $1000^{\alpha}$ & 1700 & 2500 \\
\hline $\mathrm{O}_{3}$ & Standard profile ${ }^{b}$ & $\begin{array}{l}1.1 \% \text { per year increase since } \\
1940 \text { in the troposphere }\end{array}$ & $\begin{array}{l}2.5 \% \text { per year increase since } \\
1986 \text { in the troposphere }\end{array}$ \\
\hline $\mathrm{CFCl}_{3}{ }^{\mathrm{d}}$ & 0.0 & 0.2 & 1.1 \\
\hline $\mathrm{CF}_{2} \mathrm{Cl}_{2}{ }^{\alpha}$ & 0.0 & 0.3 & 2.5 \\
\hline $\mathrm{CCl}_{4}{ }^{\alpha}$ & 0.0 & 0.15 & 0.3 \\
\hline $\mathrm{CH}_{3} \mathrm{CCl}_{3}{ }^{\mathrm{d}}$ & 0.0 & 0.15 & 1.5 \\
\hline \multicolumn{4}{|c|}{$\begin{array}{l}\text { The annual mixing ratio for } \mathrm{N}_{2} \mathrm{O} \text { and } \mathrm{CH}_{4} \text { was kept constant until } 1960 \text {. An annual } \mathrm{N}_{2} \mathrm{O} \text { increase of } 0.21 \% \text { for } 1960 \text { to } 86 \text { and } \\
\text { an annual } \mathrm{CH}_{4} \text { increase of } 1.1 \% \text { has been adopted } \\
\text { b Varies from } 25 \text { ppbv at the surface to about } 67 \text { ppbv at } 8 \mathrm{~km} \\
\text { c The concentration was increased uniformly by the same percentage from the surface to } 8 \mathrm{~km} \\
\text { dhese gases had zero abundance for the period } 1850 \text { to } 1960\end{array}$} \\
\hline
\end{tabular}

are added to the photolysis treatment as a thin layer (optical depth $=0.34$ ) that scatters $50 \%$ of the incident light backward and $50 \%$ forward. The effects of Rayleigh scattering and absorption and scattering by aerosols are also included. At the top of the model atmosphere, a zero-flux boundary condition is assumed for all chemical species. Due to the complexities introduced by higher hydrocarbons, heterogeneous processes and long photochemical relaxation times, the present version of the model does not explicitly simulate the tropospheric chemistry below $8 \mathrm{~km}$. The effects of altered chemistry below $8 \mathrm{~km}$ are included only implicitly by prescribing the projected $\mathrm{O}_{3}$ perturbations as a result of anthropogenic increases in $\mathrm{NO}_{x}$ and $\mathrm{CO}$ concentrations. The quantitative effects of climatechemistry interaction in the troposphere should therefore be viewed with caution.

\section{TRACE GAS SCENARIOS}

The 'business-as-usual' scenario for past and future trace gas perturbations used in this study is based on WMO (1985) and Ramanathan et al. (1987) and is in close proximity to that described in IPCC (1990). Table 2 summarizes the concentrations of $\mathrm{CO}_{2}, \mathrm{~N}_{2} \mathrm{O}, \mathrm{CH}_{4}, \mathrm{O}_{3}$, CFC-11, CFC-12, $\mathrm{CCl}_{4}$ and $\mathrm{CH}_{3} \mathrm{CCl}_{3}$ in the background atmosphere (year 1850) and in the present-day atmosphere (year 1986) as well as future projections to the year 2050 based on the 1986 growth rates. Prior to 1940, CFC-11, CFC-12, $\mathrm{CCl}_{4}$ and $\mathrm{CH}_{3} \mathrm{CCl}_{3}$ were virtually non-existent, hence the mixing ratio of these gases parallels their actual production rates from 1940 to 1986. The projected increases in all the trace gases from the year 1986 to the year 2050 are inferred from observed trends in emissions and atmospheric resi- dence times. The future emissions of CFCs is to be governed by the London Amendment to the Montreal Protocol. With the ratification of Amended Montreal Protocol in 1990, all countries are expected to freeze any further production of CFCs now and to reduce the production of CFCs by $50 \%$ of their 1986 level in the year 1995 followed by a complete phase-out in the year 2000 (the developing countries are allowed a 10 yr delay period in compliance with these controls). However, even with a complete cessation of production of CFCs in the year 2000, their atmospheric concentrations will still be significant for at least the next century because of their long atmospheric lifetimes (CFC-11 and CFC-12 have lifetimes of about 65 and $130 \mathrm{yr}$ respectively). It should be noted that emissions of these gases into the atmosphere will continue for a period of time after production has ceased because of their uses as refrigerants, foam blowing agents, fire retardants, etc. In view of this, we have allowed an increase in the mixing ratios of CFC-11 and CFC-12 by only 0.05 ppbv per year from their present concentrations for the period 1990 to 1995, held it constant at its 1995 level up to 2010 and reduced their mixing ratios at the rate of 0.005 ppbv per year for the period 2010 to 2050 in our scenario MP. No limitations on the emissions (via production and consumption controls) of $\mathrm{CCl}_{4}, \mathrm{CH}_{3} \mathrm{Cl}$ and $\mathrm{CH}_{3} \mathrm{CCl}_{3}$ are considered. The direct radiative effects of the background atmospheric aerosols are included by appropriately prescribing the single scattering albedo, aerosol extinction and the asymmetry factor. With a view to understanding the nature and magnitude of the 'signature' of stratospheric aerosols of volcanic origin on the surface-troposphere-stratosphere temperature, we have also used the optical properties and vertical structure of the aerosol clouds due to the El Chichon eruption of 1982 (Kent \& 
McCormick 1984, McCormick et al. 1984, MacCracken \& Luther 1984) in our time-dependent model runs.

A series of numerical experiments have been performed with the RC model as well as with the coupled chemical-radiative-transport model to assess the sensitivity of interactive stratospheric chemistry to assumed perturbations of trace gas concentration in the atmosphere. The coupled model has been adapted to conduct simulation studies (equilibrium and transient response runs) which examine the role of current and projected trace gas perturbations of anthropogenic origin on stratospheric ozone and the associated greenhouse warming. The main findings of these numerical experiments with the coupled model are discussed in the following section.

\section{RESULTS AND DISCUSSION}

\section{Model validation}

Prior to discussing the response of the chemistry and thermal structure to trace gas perturbations, it should be mentioned that the fully self-consistent vertical temperature distribution obtained with the coupled 1-D Chemical-Radiative-Transport Model for prescribed average insolation, humidity, cloudiness and background stratospheric aerosol was within a few degrees of the US Standard Atmosphere with the largest deviation $(4.9 \mathrm{~K})$ occurring near the tropopause. The temperatures were slightly higher than the standard

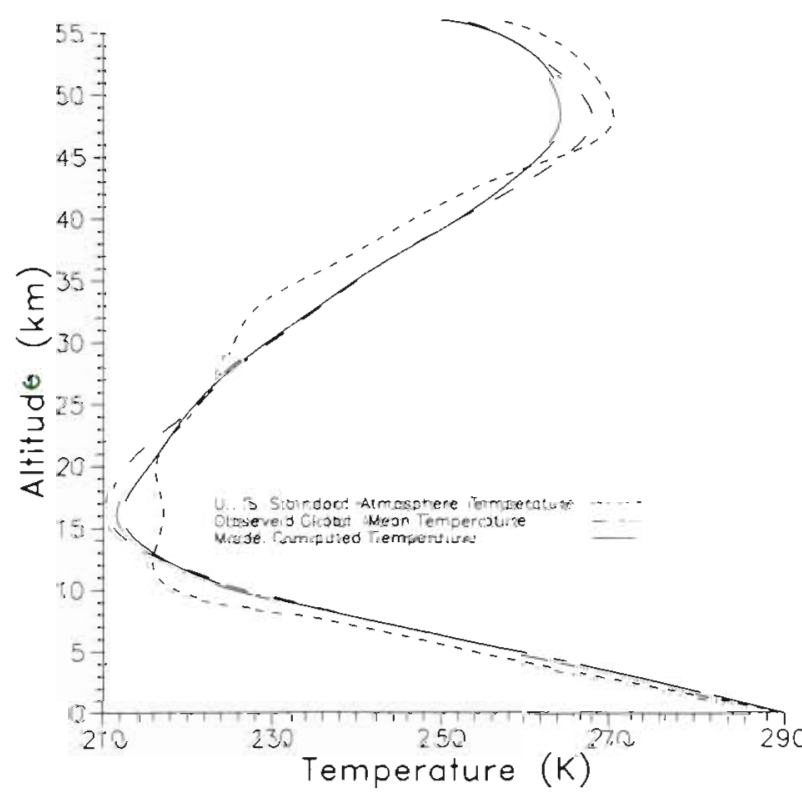

Fig. 1. Vertical distribution of temperature as predicted by the model and compared with the global mean and US Standard A.tmospheres atmosphere between 35 and $45 \mathrm{~km}$ while the location and temperature of the stratopause were well resolved in our thermal structure. In general, the model-generated vertical temperature profile was in good agreement with the observed global mean temperature profile (Fig. 1). A comparison of the stratospheric ozone mixing ratio profile simulated by the model with the profile derived from mid-latitude observations indicated that the model underestimates ozone above $40 \mathrm{~km}$ by about $4 \%$. This may be because the model is overestimating the reactive radicals $\mathrm{OH}$ and $\mathrm{HO}_{2}$ which catalyse ozone destruction in this region.

\section{Sensitivity experiments}

We describe here the results of numerical experiments performed with and without the photochemical interaction to examine the sensitivity of interactive stratospheric chemistry to doubling of each of the trace gases individually. The major findings are summarized in Table 3. In the absence of interactive chemistry, the

Table 3. Model-computed changes in total column ozone and surface temperature due to steady-state perturbations of anthropogenic trace gases

\begin{tabular}{|lccc|}
\hline $\begin{array}{l}\text { Trace } \\
\text { gases }\end{array}$ & $\begin{array}{c}\text { Column } \\
\text { ozone } \\
\text { change }\end{array}$ & $\begin{array}{c}\text { Surface temperature change } \\
\text { No } \\
\text { chemistry }\end{array}$ & $\begin{array}{c}\text { With } \\
\text { chemistry }\end{array}$ \\
\hline $2 \times \mathrm{CO}_{2}$ & $+4.7 \%$ & $+1.78 \mathrm{~K}$ & $+1.85 \mathrm{~K}$ \\
$2 \times \mathrm{CH}_{4}$ & $+4.9 \%$ & $+0.36 \mathrm{~K}$ & $+0.67 \mathrm{~K}$ \\
$2 \times \mathrm{N}_{2} \mathrm{O}$ & $-9.4 \%$ & $+0.35 \mathrm{~K}$ & $+0.37 \mathrm{~K}$ \\
$2 \times \mathrm{CFC}_{5}$ & $-6.3 \%$ & $+0.08 \mathrm{~K}$ & $+0.09 \mathrm{~K}$ \\
\hline
\end{tabular}

calculated change in the surface temperature due to doubled- $\mathrm{CO}_{2}$ concentration (330 to $660 \mathrm{ppmv}$ ) is $1.78 \mathrm{~K}$, a sensitivity which, although consistent with most RC models, is at the lower end of the currently accepted range of 1.5 to $4.5 \mathrm{~K}$ derived from GCM studies (Bolin 1986). This discrepancy could be attributed to the multi-dimensional feedbacks inherent in GCMs. The largest $\mathrm{CO}_{2}$-induced temperature change of $-11.3 \mathrm{~K}$ was found in the stratosphere at about $48 \mathrm{~km}$. As a result of the interactive chemistry the maximum $\mathrm{CO}_{2}$-induced cooling was reduced to $-8.7 \mathrm{~K}$. As temperature decreases, the rate of ozone loss decreases, leading to an increase in the local ozone concentration; increased ozone heating thus gives a higher temperature (negative feedback on stratospheric temperature perturbations). The chemical feedback effect on the surface temperature change due to doubling of $\mathrm{CO}_{2}$ in the atmosphere is small and positive, increasing the surface temperature change 
from 1.78 to $1.85 \mathrm{~K}$ (Table 3 ). This increase is attributed to the calculated increase in ozone concentration near $28 \mathrm{~km}$ resulting in a larger infrared opacity as seen from the surface, trapping more IR radiation in the troposphere and lower stratosphere. In addition, a larger local ozone concentration gives augmented solar heating in the mid-stratosphere. The total ozone column increase due to doubling of $\mathrm{CO}_{2}$ calculated with the coupled model is $4.7 \%$, a value close to that obtained by Wuebbles (1983).

The steady-state change in the local ozone concentration as a function of altitude shows an increase of

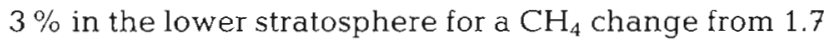
to 3.4 ppmv. The modelled impact of doubled methane on the ozone column is an increase of $4.9 \%$. The surface temperature change, $+0.67 \mathrm{~K}$, includes both the direct greenhouse effect of the methane infrared opacity $(+0.36 \mathrm{~K})$ and an indirect positive enhancement $(+0.31 \mathrm{~K})$ due to the ozone increase in the lower stratosphere. In the upper stratosphere (above $40 \mathrm{~km}$ ), a marked decrease in local ozone $(-7 \%)$ is obtained with doubled $\mathrm{CH}_{4}$. The largest thermal impact of increased $\mathrm{CH}_{4}$ is also observed near the stratopause (local cooling by $9.7 \mathrm{~K}$ ). For the doubled- $\mathrm{CH}_{4}$ case, methane oxidation increases stratospheric $\mathrm{H}_{2} \mathrm{O}$ giving enhanced $\mathrm{HO}_{x}$ levels. $\mathrm{HO}_{x}$-catalysed ozone destruction dominates in this region causing more rapid ozone destruction. These results indicate that, although only $10 \%$ of the total ozone is located above $40 \mathrm{~km}$, future methane increases could significantly contribute to local ozone depletion there.

Both $\mathrm{N}_{2} \mathrm{O}$ and $\mathrm{CFC}_{5}$ are associated with atmospheric removal of $\mathrm{O}_{3}$ through catalytic processes involving chlorine and nitrogen cycles. The doubling of $\mathrm{N}_{2} \mathrm{O}$ from its present-day mixing ratio yields a column ozone decrease of $9.4 \%$. The associated surface temperature change is $+0.37 \mathrm{~K}$. The combined impact of the doubling of chlorofluorocarbons and chlorocarbons from their present-day mixing ratio on the calculated column ozone change is a decrease by $6.3 \%$. A moderate increase in ozone was obtained in the lower stratosphere which led to local heating, thus further reducing the efficiency of $\mathrm{NO}_{x}$ in destroying ozone. The dominant role of CFCs was noticed in the depletion of ozone in the 30 to $40 \mathrm{~km}$ region. The calculated change in the atmospheric temperature profile due to CFC increases revealed maximum cooling $(23 \mathrm{~K})$ to be at an altitude of $48 \mathrm{~km}$. The surface temperature change was $+0.09 \mathrm{~K}$.

The above results enable us to identify the sign and magnitude of feedback between the chemistry and the thermal structure of the atmosphere for trace gas perturbations of anthropogenic origin based on recent chemical reaction rate data sets. The calculated ozone and temperature changes due to individual perturbations in trace gas concentrations in our model are consistent with other 1-D model calculations when compared under equivalent conditions (Brasseur et al 1985, Ramanathan et al. 1985, Hansen et al. 1989).

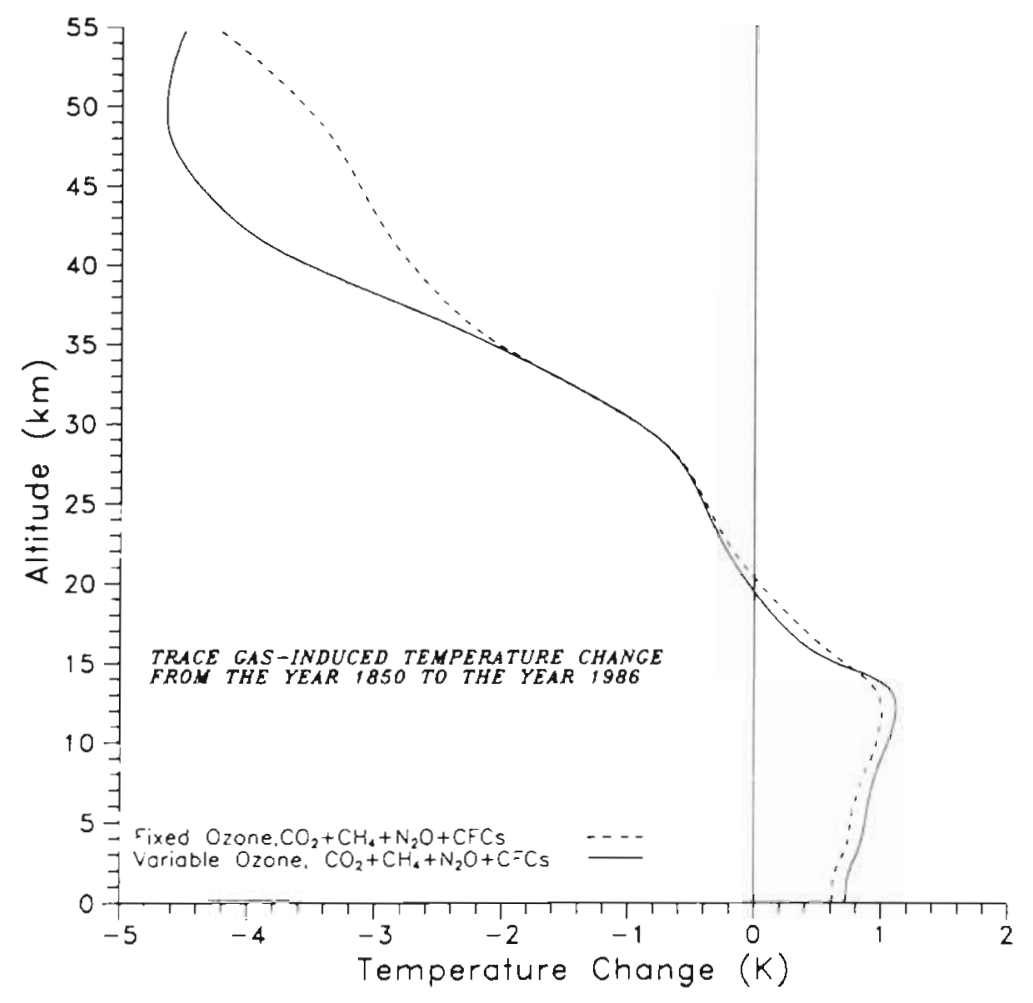

Fig. 2. Model-computed changes in vertical thermal structure for the period 1850 to 1986 due to increase in atmospheric trace gases with and without photochemical interaction 
Next, we present the coupled model results, which consider the trace gas perturbation scenarios (scenario BAU as outlined in Table 2 and scenario MP as described in the 'Trace Gas Scenarios' section above). The objective of these experiments was to infer changes in stratospheric ozone and in the thermal structure of the atmosphere, from the past to presentday, and also to estimate changes which may occur by the middle of the next century. The future trace gas perturbations represent plausible scenarios for these chemical species for the middle of the next century.

\section{Equilibrium response to observed/projected trace gas trends}

The coupled 1-D chemical-radiative-transport model has been employed to interactively predict the vertical distribution of atmospheric ozone and the thermal structure of the atmosphere for the years 1850,1986 and 2050. Figs. $2 \& 3$ show the computed surface and atmospheric temperature changes under equilibrium conditions with radiative-photochemical interaction for the periods from 1850 to 1986 and 1850 to 2050 respectively. Also shown in Figs. $2 \& 3$ are the computed surface and atmospheric temperature changes due to the perturbations in trace gas scenarios given in Table 2 (scenario BAU) but with no radiation-chemistry coupling (fixed ozone). The corresponding changes in atmospheric ozone relative to the background atmosphere of 1850 are illustrated in Fig. 4.

The greenhouse warming at the surface for the period 1850 to 1986 due to increases in trace gases, resulting from the direct radiative effect alone, is $0.61 \mathrm{~K}$ (Fig. 2). This global mean warming is enhanced to $0.72 \mathrm{~K}$ when we take into account the indirect thermal effects caused by the net ozone change due to the interactive photochemistry. In the stratosphere, the increased loss of energy to space caused by the radiative effect of increases in trace gases leads to local cooling (Figs. $2 \& 3$ ). Further, as is evident from Fig. 4, the trace gas increase from the year 1850 to the year 1986 could have already contributed to a decline in the stratospheric ozone between 30 to $48 \mathrm{~km}$, reaching a maximum of $10.7 \%$ at $42 \mathrm{~km}$, although a net increase in the total column amount is observed. These changes in the vertical ozone distribution are notably reflected in the surface and atmospheric temperatures. The stratospheric cooling is substantially enhanced by the indirect effects of the local ozone decreases resulting from the radiative-photochemistry interactions.

The model results indicate that the direct radiative effect of the greenhouse warming at the Earth's surface with respect to the present-day atmosphere would be $1.93 \mathrm{~K}$ (Fig. 3) by the middle of the next century. With the interactive chemistry, a considerable loss of stratospheric ozone is expected by the year 2050 (a maximum of over $43 \%$ at an altitude of $40 \mathrm{~km}$ ) and this
Fig. 3. As Fig. 2 except for the period 1850 to 2050

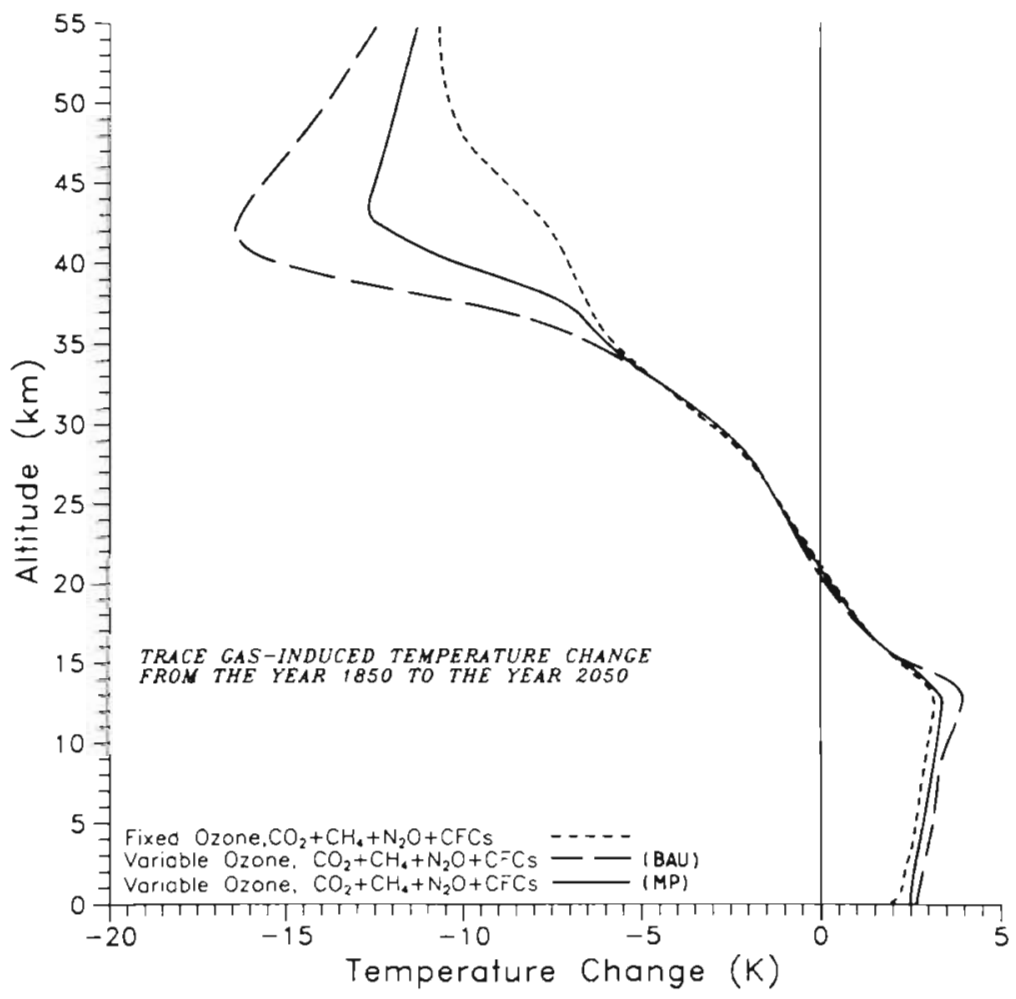


could enhance the surface warming by $33 \%$ from $1.93 \mathrm{~K}$ to $2.57 \mathrm{~K}$ (scenario BAU). The stratospheric ozone loss expected by the middle of the next century is likely to make a large contribution to the cooling of the middle stratosphere. The stratospheric cooling of $10.68 \mathrm{~K}$ obtained in our model simulation due to the radiative interaction of projected trace gas perturbations alone is likely to be enhanced to over $16.41 \mathrm{~K}$ when the photochemistry is coupled to radiative processes in the atmosphere (scenario BAU). Another interesting feature in the calculated change of the thermal structure of the atmosphere from the year 1850 to the year 2050 is that the altitude of maximum cooling in the stratosphere drops by about $6 \mathrm{~km}$ with the radiation-photochemistry interaction (Fig. 3).

As a result of controls on production of CFCs (scenario MP), the sharp decline in local ozone at $40 \mathrm{~km}$ is substantially reduced (Fig. 4). The maximum loss in ozone for the year 2050 of $17 \%$ is obtained at about $38 \mathrm{~km}$ in our model calculations. The predicted total column change in ozone expected by the middle of the next century is only $2.9 \%$. For scenario MP, the greenhouse-induced surface warming for the year 2050 is obtained as $2 \mathrm{~K}$ while a local mid-stratospheric cooling of $12.6 \mathrm{~K}$ is predicted (Figs. $3 \& 4$ ).

The stratospheric cooling projected for the middle of the next century as a consequence of greenhouse warming due to increases in atmospheric trace gases (scenarios BAU and MP) could lead to substantial perturbations in the dynamics of the atmosphere. In addi- tion, decline in stratospheric ozone may induce changes in tropospheric ozone, through changes in ultraviolet radiation (the tropospheric ozone level is likely to be enhanced in regions with high levels of $\mathrm{CO}$ and $\mathrm{NO}_{x}$ ).

The global mean surface temperature change for the period 1850 to 1986 due either to the radiative effects of increases in atmospheric trace gases alone, or to the combined effects of radiation-chemistry interaction, is marginally lower in our model than the temperature change reported by other studies (Mitchell 1989).

\section{Transient response to projected trace gas trends}

The equilibrium thermal response of the atmosphere to perturbations in greenhouse trace gases may not be considered realistic. With a view to predicting the sequence of future global warming, we have calculated the transient response of the atmosphere to time-varying trace gas concentrations based on appropriate growth rates for scenarios BAU and MP (expected without/with the implementation and full participation of the London Amendment to the Montreal Protocol on controlling the substances that deplete the ozone layer). The time-dependent model run with radiationchemistry interaction was initiated with the equilibrium thermal structure for the year 1980 (to economise on limited computing resources) and continued through a $70 \mathrm{yr}$ period to the year 2050 . Here, we have

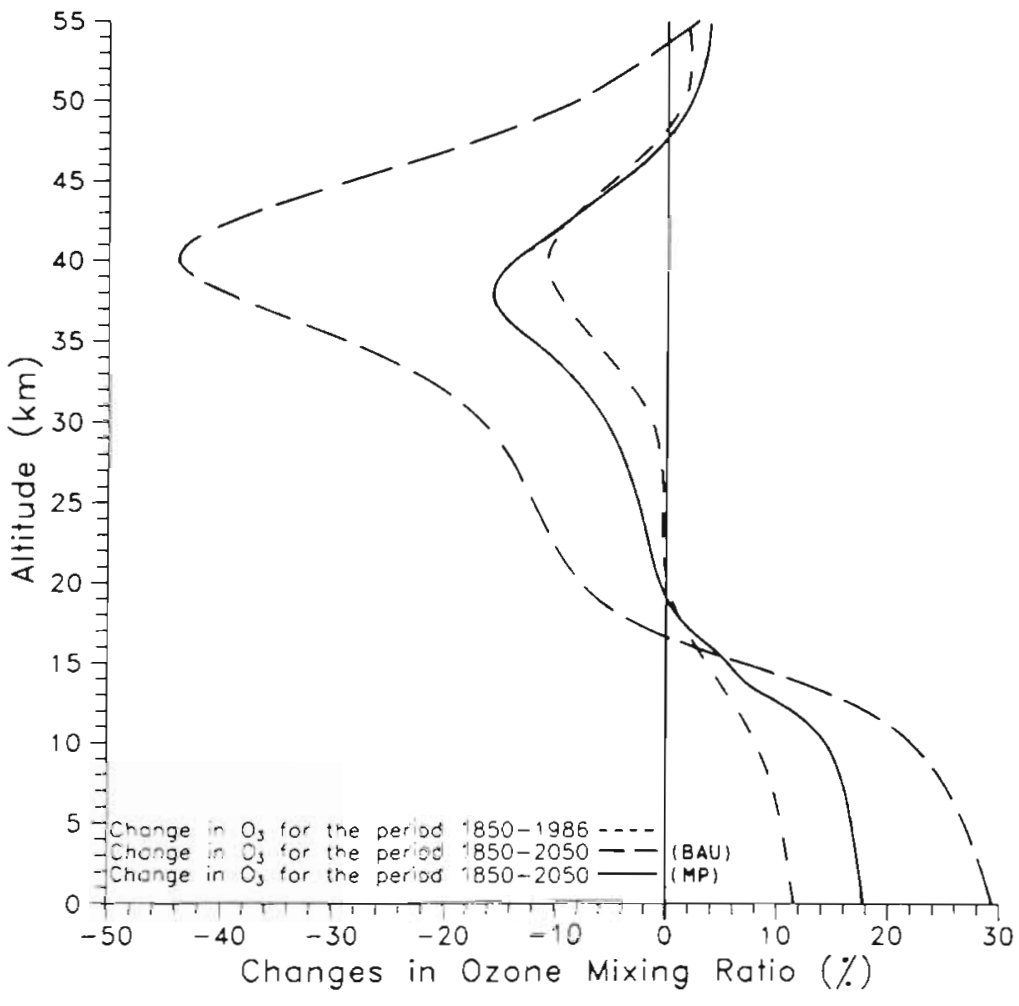

Fig. 4. Model-computed changes in vertical profile of ozone for the periods 1850 to 1986 and 1850 to 2050 due to increases in atmospheric trace gases 
included the heat capacity of the underlying ocean with a $50 \mathrm{~m}$ mixed layer which takes account of the influence of ocean's thermal inertia. The calculations also include the radiative effect of the El Chichon volcanic eruption on the thermal structure.

Fig. 5 shows the model-simulated changes in the global mean temperature at 3 selected levels in the atmosphere as a function of time for the transient response experiments described above. The surface warming rises steadily except for a brief period when it is interrupted by a temporary cooling of $0.8 \mathrm{~K}$ due to the increase in dust load resulting from the El Chichon volcanic eruption. The recovery period from the sudden cooling is a little over $2 \mathrm{yr}$. The modelled response to El Chichōn is greater than the observed cooling, probably because of concurrent background warming associated with an El Niño event of 1982. The predicted global mean surface warming by the year 2050 for scenario BAU is $2.6 \mathrm{~K}$. This surface warming is likely to be marginally reduced to $2 \mathrm{~K}$ with the restrictions on CFC production (scenario MP).

The volcanic eruption also caused marked warming of the lower stratosphere and the model predicted maximum warming of about $4.2 \mathrm{~K}$ at $22 \mathrm{~km}$ (Fig.5). Interestingly, at this level, no significant warming/cooling trends as a result of trace gas increases are predicted. In the middle stratosphere $(40 \mathrm{~km})$, the temperature drops progressively except for a temporary warming of $0.8 \mathrm{~K}$ in the year 1983 following the $\mathrm{El}$ Chichon eruption. For the scenarios BAU and MP, the stratospheric cooling at $40 \mathrm{~km}$ in the year 2050 is predicted to be about $16.4 \mathrm{~K}$ and $12.6 \mathrm{~K}$ respectively. Limited support for the model results comes from radiosonde/satellite data for 1964 to 1987 , which indicate a cooling trend for the middle stratosphere $(30 \mathrm{~km})$ in the mid- to high latitudes $\left(25\right.$ to $\left.90^{\circ} \mathrm{N}\right)$ of the Northern Hemisphere (Johnson et al. 1988).

For scenario BAU, a local maximum ozone depletion of $43 \%$ is predicted in our time-dependent model calculations at about $40 \mathrm{~km}$ for the year 2050. The decreased solar absorption due to the ozone decline cools the stratosphere. This cooling is further enhanced by the reduction of IR absorption (by the $9.6 \mu \mathrm{m}$ band of $\mathrm{O}_{3}$ ) in the stratosphere of surface-troposphere emissions. For scenario MP, the local maximum ozone depletion in the mid-stratosphere is restricted to only $17 \%$ in our model calculations.

The total ozone column mixing ratio is predicted to decline by $12.7 \%$ by the year 2050 in our transient response model calculations for scenario BAU. With emission restrictions on CFCs as incorporated in scenario MP, this decline in total column ozone for the year 2050 would be limited to only $2.9 \%$. The expected decline is found to be more rapid (double the rate prior to the year 2015 for scenario BAU) in the last 3 decades of the model simulation.
Fig. 5. Model-calculated changes in surface and stratospheric temperatures as a function of time

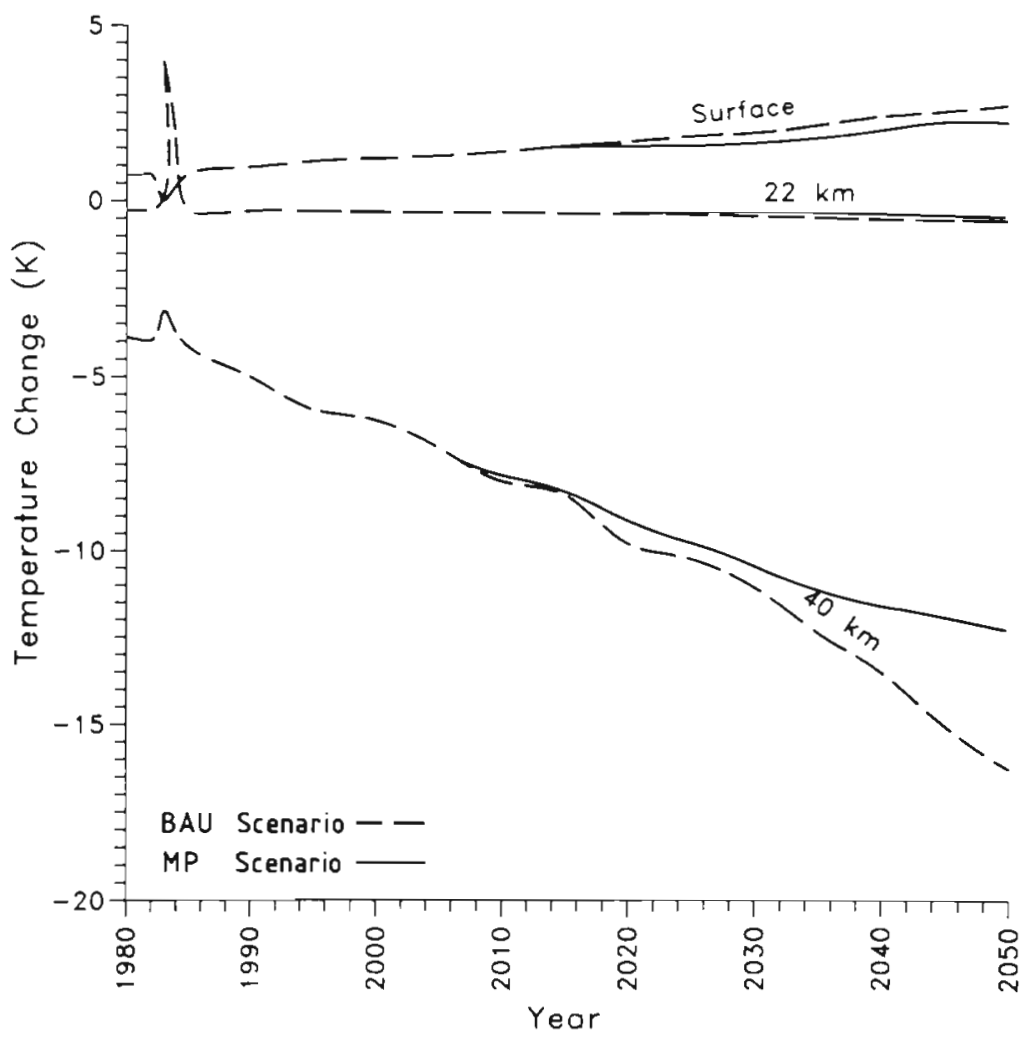




\section{CONCLUSIONS}

Calculatios using a 1-dimensional interactive chemical-radiative-transsport model confirm that increasing concentrations of anthropogenic trace gases should considerably modify the ozone and temperature distributions in the atmosphere. Photochemical processes seem to dominate in the middle and upper stratosphere. Large variations in the local concentration of ozone in the middle stratosphere (near $40 \mathrm{~km}$ ) are predicted for the year 2050 based on our projections of future emissions of trace gases. Recent control measures on emission of CFCs under the amended Montreal Protocol agreement will limit the CFCs growth rate resulting in a smaller impact of CFCs on future greenhouse warming. The large local $\mathrm{O}_{3}$ decline and associated stratospheric cooling could, however, still cause changes in the atmospheric circulation. The surface warming projections presented here represent the global mean warming and therefore indicate general trends rather than specific geographical variations. Regional warming tendencies can only be fully considered using a 3-dimensional dynamical model incorporating all the physical and chemical interactions described in our simple model. As yet, such models do not exist.

The complex nature of feedback processes in the stratosphere implies that they can be fully understood only through interactive modelling of the radiativephotochemical-dynamical system. Our model, despite the lack of a true spatial domain, serves as a useful tool for assessing the expected impacts on temperature of stratospheric ozone changes due to anthropogenic activities, enabling a detailed examination of the role of radiation-photochemistry interaction in the stratosphere. Efforts are now underway to construct a 2dimensional radiative-photochemical-transport model in the meridional-vertical plane with parametrization of horizontal transport processes by zonally symmetric eddy mechanisms. The inclusion of a comprehensive tropospheric chemistry should improve the accuracy of the model in predicting future possible variations in tropospheric ozone and the associated global temperature changes.

Acknowledgements. The Royal Society of London and the Climatic Research Unit (CRU) of the University of East Anglia provided financial support to the first author for his visit to CRU which is gratefully acknowledged. The first author had useful discussions with Prof. P. J. Crutzen and Di C. Brühl of the Max Planck Institute for Chemistry, Mainz, Germany. They generously provided a copy of their photochemistry model code and its description which helped in formulating the model described and used in this work. The authors thank Prof. T. M. L. Wigley and Dr P. M. Kelly for their critical review of the manuscript and useful suggestions. We also thank Christine Jeffery for typing the manuscript.

\section{LITERATURE CITED}

Bolin, B. (1986). How much $\mathrm{CO}_{2}$ will remain in the atmosphere? In: Bolin et al. (eds.) The greenhouse effect, climatic change and ecosystems. SCOPE 29, John Wiley, New York, p. 93-155

Brasseur, G., Rudder, A., Tricot, C. (1985). Stratospheric response to chemical perturbations. J. Atmos. Chem. 3: $261-288$

Brasseur, G., Simon, P. C. (1981). Stratospheric chemical and thermal response to long-term variability in solar UV irradiance. J. geophys. Res. 86: 7343-7362

Brühl, C., Crutzen, P. J. (1984). A radiative-convective model to study the sensitivity of clinate and chemical composition of a variety of human activities. In: Ghazi, A. (ed.) Stratosphere, Proc. of a Working Party Meeting, Commission of the European Communities, Brussels, p. 85-94

Brühl, C., Crutzen, P. J. (1988). Scenario of possible changes in atmospheric temperatures and ozone concentrations due to man's activities estimated with a one-dimensional coupled photochemical climate model. Clim. Dyn. 2: 173-203

Cariolle, D., Déqué, M. (1986). Southern Hemisphere medium-scale waves and total ozone disturbances in a spectral general circulation model. J. geophys. Res. 91: 10825-10846

Cess, R. D., Coakley, J. A., Kolensnikov, P. M. (1981). Stratospheric volcanic aerosols: a model study of interactive influences upon solar radiation. Tellus 33 (5): 444-452

DeMore, W. B., Margitan, J. J., Molina, M. J., Watson, R. T., Golden, D. M., Hampson, R. F., Kurylo, M. J., Howard, C. J., Ravishankara, A. R. (1985). Chemical kinetics and photochemical data for use in stratospheric modeling. Evaluation 7: JPL Publ. 85-37, p. 217

DeMore, W. B., Molina, M. J., Sander, S. P., Golden, D. M., Hampson, R. F., Kurylo, M. J., Howard, C. J., Ravishankara, A. R. (1987). Chemical kinetics and photochemical data for use in stratospheric modeling. JPL Publ. 87-41, p. 317

DeMore, W. B., Sander, S. P., Golden, D. M., Molina, M. J., Hampson, R. F., Kurylo, M. J., Howard, C. J., Ravishankara, A. R. (1990). Chemical kinetics and photochemical data for use in stratospheric modeling. JPL Publ. 90-1, p. 217

Hansen, J., Lacis, A., Prather, M. (1989). Greenhouse effect of chlorofluorocarbons and other trace gases. J. geophys. Res. 94: $16417-16421$

Intergovernmental Panel on Climate Change (1990). Scientific assessment of climate change. WMO/UNEP Rep., 1990 p. 365

Johnson, K. W., Lehman, R. L., Gelman. M. E., Miller, A. J., Nagatani, R. M. (1988). Stratospheric temperature changes: 1964-1987. EOS (Trans. Am. Geophys. Un.) 69. 311-318

Kaye, J. A., Rood, R. B. (1989). Chemistry and transport in a three-dimensional stratospheric model: chlorine species during a simulated stratospheric warming. J. geophys. Res. 94: $1057-1083$

Kent, G. S., McCormick, M. P. (1984). SAGE and SAM-II measurements of global stratospheric aerosol optical depth and mass loading. J. geophys. Res. 89: 5303-5314

Kiehl, J. T., Ramanathan, V (1983). $\mathrm{CO}_{2}$ radiative parametrization used in climate models: comparison with narrow band models and with laboratory data. J. geophys. Res. 88 : 5191-5202

Kinnison, D. E., Johnston, H. S., Wuebbles, D. J. (1988). Ozone calculations with large nitrous oxide and chlorine changes. J. geophys. Res. 93: 14165-14175 
Lacis, A. A., Hansen, J. E. (1974). A parameterisation for the absorption of solar radiation in the earth's atmosphere. $\mathrm{J}$. Atmos. Sci. 31: 118-133

Lal, M., Jain, A. K. (1989). Increasing anthropogenic constituents in the atmosphere and associated climatic changes. In: Cheremisinoff, P. N. (ed.) Encyclo. Environ. Cont. Techno., Vol. 2., Chap. 18. Gulf Publishing, Houston, p. $735-762$

Lal, M., Ramanathan, V (1984). The effects of moist convection and water vapor radiative processes on climate sensitivity. J. Atmos. Sci. 41: 2238-2249

MacCracken, M. C., Luther, F. M. (1984). Preliminary estimate of the radiative and climatic effects of the El Chichon eruption. Geofis. Int. 233: 385-401

McCormick, M. P., Swissler, T J., Fuller, W. H., Hunt, W. H., Hunt, M. T. (1984). Airborne and ground-based lidar measurements of the El Chichonn stratospheric aerosol from $90^{\circ} \mathrm{N}$ to $56^{\circ} \mathrm{S}$. Geofis. Int. 23: 187-221

Mitchell, J. F. B. (1989). The greenhouse effect and climate change. Rev. Geophys. 27: 115-139

Prather, M. J., Watson, R. T. (1990). Stratospheric ozone depletion and future levels of atmospheric chlorine and bromine Nature, Lond. 344: 729-733

Ramanathan, V. (1976). Radiative transfer within the earth's troposphere and stratosphere: a simplified radiative-convective model. J. Atmos. Sci. 33: 1330-1346

Ramanathan, V., Callis, L., Cess, R., Hansen, J., Isaksen, I., Kuhn, W., Lacis, A., Luther, F., Mahlman, J., Reck, R., Schlesinger, M. (1987). Climate-chemical interactions and

Editor: G. Esser effects of changing atmospheric trace gases. Rev. geophys 25 (7): 1441-1482

Ramanathan, V., Cess, R. D. (1974). Radiative transfer within the mesospheres of Venus and Mars. Astrophys. J 188: $407-416$

Ramanathan, V., Cicerone, R. J., Singh, H. B., Kiehl, J. T. (1985). Trace gas trends and their potential role in climate change. J. geophys. Res. 90: 5547-5557

Rood, R. B., Kaye, J. A., Nielson, J. E., Schoeberl, M. R., Geller, M. A. (1987). Nitric acid forest experiments. Phys. Scr. 36: $337-354$

Rose, K. (1986). The stratospheric winter polar vortex simulated as a material entity. J. Atmos. Terr. Phys. 48: 1197-1202

Vupputuri, R. K. R. (1988). Potential effects of anthropogenic trace gas emissions on atmospheric ozone and temperature structure and surface climate. Atmos. Environ. 22: $2809-2818$

Wang, W. C., Molnar, G. (1985). A model study of the greenhouse effects due to increasing atmospheric $\mathrm{CH}_{4}, \mathrm{~N}_{2} \mathrm{O}$, $\mathrm{CF}_{2} \mathrm{Cl}_{2}$ and $\mathrm{CFCl}_{3}$. J. geophys. Res. 90: 12971-12980

World Meteorological Organisation (1985). Atmospheric ozone: assessment of our understanding of the processes controlling its present distribution and change. Rep. 16, Global Ozone Res. and Moni. Proj., Chap. 3. WMO, Geneva, p. 88-100

Wuebbles, D. J. (1983). A theoretical analysis of the past variations in global atmospheric composition and temperature. Rep. UCRL-53423, Lawrence Livermore Nat. Lab., Calif.

Manuscript first received: May 21, 1990

Revised version accepted: December 18, 1990 